\title{
Research and Application of Modern Distance Physical Education
}

\author{
Yongjie Liang \\ Department of Sports, Guizhou University of Finance and Economics, Guiyang 550025, China \\ gzcd2012@163.com
}

Keywords: Modern Distance Education, network technology, Physical Education

\begin{abstract}
Traditional physical education has single teaching content, teaching methods are backward, learning time constraints and other issues, and however, network technology as the representative of modern distance education is having the content and form of new, highly interactive teaching, breaking the advantage of time and space constraints, etc., improve the educational effect, it is increasingly being applied to education. This paper discusses the advantages and disadvantages of distance education, analyzes the three systems of Remote Physical Education, proposed the distance physical education process, to provide theoretical support for remote physical education in China.
\end{abstract}

\section{Introduction}

Traditional physical education major way is through direct instruction or correspondence. Through direct instruction of students, although full-time learning education, but the influence of traditional education and people's attitudes, teaching effect is not very optimistic. However, through correspondence students, often subject to influence students to participate in educational work, time and energy are limited, the whole process is completed by the participants themselves independent learning. This education is obviously insufficient,students only some paper material, content of a single constant, all rely on student individual ability, lead to learning ineffective. However, network technology as the representative of modern distance education is a new form of education, is an important model for students can lifelong learning. Currently, distance education development of the country very quickly, distance education institutions springing up, eager to set up, and in the implementation and planning of curriculum-based IT services, such as using the Internet, e-mail, video conferencing systems, network teaching platform, on-demand systems, etc. form, these courses serve to overcome the limitations of traditional education time, space, resources and other aspects, with real-time, adaptive, networked, interactive features, to the greatest extent to meet the various demands of learners, thus, the modern distance education has become a domestic students to continue their education major trends.

\section{Theoretical Analysis of Physical Education in Modern Distance}

1. Factor analysis of distance sports education teaching. Due to their form of new, network technology as the representative of education, interactive features popular. Physical Education in Distance Education out of the limited resources, lack of time, in the form of backward difficulties, we achieved good results in teaching. Three elements of classical teaching doctrinethinks that the teaching process by teachers, learners and teaching materials of three parts. For sports educations, learning three elements are: learners, learning materials and learning helper.For remote education, the student is a learner, Learning materials can hang on the Internet, the school has taken many forms ${ }^{[1]}$; learning helper was distance learning instructor, the teacher can marking student work, and learning materials can be updated in real time. Distance education depend communication technology, real-time interaction, timely data updates and online job marking, learning trajectories can be found, but also the interaction between the students,disambiguation answer.

2. Psychology factor analysis of distance sports education.Psychologists Robinson put forward "expectations of price and volume pattern," referring to reference group has a major impact on the formation of students' learning attitude, if the reference group to participate in learning to 
hold negative value, then students will be negative to the force, it is difficult to have effective learning takes place ${ }^{[2]}$. Distance education students may be different in some way connected together, discuss topics of mutual interest, confusing issue, through this platform so that students greatly improve the professional knowledge and skills. Such as QQ group, micro-channel, microblogging and other connections very innovative, attractive, into positive energy for the trainees distance training, improve the training effect.

3. The information literacy analysis of distance education. Information literacy is first proposed by Paul cosgrove kittim, he said: "With a large number of information tools and key information technology resources and skills to get the problem solved." ${ }^{[3]}$. For physical education students, they already have the professional and basic knowledge of the industry, for the professional (industry) of the problem is more deep thinking, can answer simple questions. Physical education must reflect the students' self-learning ability; teachers do not have to urge students to learn, just provide good information to issue guidance, the participants themselves will be able to complete the learning task very well. Remote training provides students with massive learning materials, this is much more than the traditional correspondence education can provide information, and students can read and understand themselves. In 1924, American psychologist Thorndike experimentally confirmed, in adulthood, people still have a wide range of learning ability,this thesis got many subsequent learning psychologist corrections and deepens ${ }^{[4]}$.

\section{Network Technology in Physical Education}

1. Three systems of Distance Physical Education System. Our teaching model including the implementation of teaching physical education, monitoring teaching and evaluate teaching methods and means,adopts modular structure, concrete can be divided into three modules: management module, teaching modules and teaching support service module ${ }^{[5]}$.In remote teaching, distance sports education system is divided into three subsystems, namely knowledge system, management, supervision system and communicates with each other. (1) The system is the core of traditional knowledge, including several subsystems curriculum, teaching design and data collection, is the key to success or failure of Physical Education.The sports education practicality is very strong, sports need technical and tactical instruction, there are many sports physiology psychology with maps, these teaching tools in computer remote training is very easy to break, by 3Dmax, PS, Dreamweaver software to production technology, diagrams into course content, student based on these data are easy to grasp. Students can also practice their own production to become pictures, videos uploaded to a public platform,everyone to discuss research.(2) Supervision and management system is one of the remote physical education quality assurances,through the system to urge students to learn and finish the homework, the system includes a test system, job submission and monitoring sub-class. Modern Distance Education Integrated communications technology, multimedia technology and network technology, is through the Visual Basic, Flash and other programming language Settings information group.Schools can also open up the relevant section on your own website for remote publishing and guidance for students. (3) The exchange system is the essence of distance adult education, including teacher exchanges and student exchanges between the two subsystems students,through the communication to achieve the participants improve disambiguation and professional answer, through QQ, MSN, E-mail, one-to-one or one-to-many tutoring. Microblogging, letter, etc. are currently very popular third-party platform; teachers can publish information via these platforms, assignments.

\section{Based on analysis of distance sports education process to investigate.}

(1) The student needs analysis. The purpose of modern education is deposited into student knowledge upgrading, after some time of work, a lot of knowledge and skills cannot meet the work, we must learn to enhance capacity and increase knowledge, improve their ability.(2) Resource browsing. One of the advantages of the remote PE is enriched and updated teaching resources in a timely manner.School physical education and guidance teacher according to the teaching target collection of teaching resources, for example, basketball teaching can accord the case of NBA video game of basketball technique and the referee just called a penalty on the aspects of teaching. Sports 
physiology can be animated by teaching visual novel, attractive, long retention teaching content and easy access can be repeated thinking. (3) Job evaluation. Remote Physical education is different from ordinary physical education; students mostly have a certain professional basis, so for a deeper understanding of sports, it has its own views on certain phenomenon or problem, the instructor can give some of the issues based on what was learned and the actual situation, so that students in the form of small paper statements out and spread exchange platform for teachers and other students to observe and discuss. (4) AC applications. Each student has career confusion, confusion and other knowledge, in the remote teaching, instructor designated as public communication of a certain time period, students can make their own doubts, questions, you can also disambiguation answer for others, the wisdom is infinite, students can also guide teachers on their own learning experience confusion or other participants to leave a message. Of course, ask questions, answer questions can be used as indicators of student achievement is outstanding, to urge each student to actively participate in teaching. (5) Oversight Services. Any study must be designed to evaluate the appropriate monitoring mechanisms in order to continue to deepen, achieved good results, sports distance training as well. For evaluation mechanisms from the following three aspects: first, term papers, each participant in a semester should provide their academic papers, independently, according to the industry (professional) characteristics, words not too much, but it must be targeted, novelty. The second is based on the information provided, the random composition exam, conducted limited time to answer. Third is to conduct the evaluation based on learning time and learning.

\section{Conclusions}

In a word, Modern Distance Education due to its own merits, the full potential of education, the educated and network resources,realize the will of the educates to continue education, is helpful for educators to correct teaching idea, education content, teaching means and teaching material teaching, etc. Modern educational technology represents the future direction of continuing education, with the sound, shape, sense of technology breakthroughs, virtual reality technology attention, this distance education technology to consider the feelings of the greatest educated, whom creates an immersive involved in learning research platform.

\section{Reference}

[1] Fafen Luo.The influence factors of distance learners finish school research [D]. Guangzhou: South China Normal University, master's degree thesis, 2007.

[2] Meiping Huang.Shallow theory based on modern distance education of adult higher education [M]. Beijing: Chinese school education, 2009.

[3] Fancheng Lin. Construction of "Trinity" Adult Distance Learning Support Service System [J].Journal of qufu normal university (natural science edition), 2008 (5).

[4] Yuanyuan Yan. Modern Distance Education Learning Support Services Case Study - in Yunnan Radio and TV University Learning Support Services Case [D].Kunming: yunnan university master's degree thesis, 2011.

[5] Chunlin Ma.Mainly based on the adult mathematics teaching under the modern distance education technology [J]. Yushu Wai teaching, 2007 (5). 